\title{
Digital literacies and academic integrity
}

\author{
A Nicole Pfannenstiel \\ Arizona State University \\ niki@asu.edu
}

Keywords: literacy, new media, academic integrity, academic literacy, digital literacy

\begin{abstract}
The everyday use of new media technology has inevitably resulted in a shift in students' learning and literacy practices. When tracked into the classroom, these new literacies have consequences for scholarly practice, such as when students complete assignments that draw on source material of dubious academic credibility, which leads to conflict with their teacher's expectations about academic integrity. For instance, when students build on their new media literacy skills by creating mashup videos for YouTube, they will probably exercise different ideas about fair use of source material and acknowledgement practices than those upheld in academe. However, educators can bridge the gap between these everyday media practices and more academic expectations about integrity and appropriate discourse by explicitly discussing the different protocols at play in student use of new media technologies and activities. Allowing for usage of 'home-based' literacy practices gives educators the room to explore alternative academic literacies, which fit new classroom dynamics, while also meeting the needs of more discipline specific academic discourse. This paper will discuss some ways to begin conversations about literacy that will lead to students engaging with issues of academic integrity, arguing that decontextualised moralising about plagiarism, for example, serves little purpose. Approaching academic integrity as itself a form of literacy practice allows educators to build on existing literacies by contextualising these in relation to academic norms.
\end{abstract}

\section{Introduction}

The popular resurgence of the vampire has seen a steady stream of mashup videos on YouTube devoted to the genre of vampire slaying. In another domain, the music industry is being forced to contend with controversial 'grey' albums, like those of DJ Danger Mouse, who mashed together the Beatle's 'White Album' and Jay-Z's 'The Black Album,' to create an entirely new work (Werde, 2004). We live in a world where information is available at our finger tips in online encyclopediac form, yet that information is continually in flux (Tapscott and Williams, 2006, p. 10-11). In the age of blogs, mashups, smashups and Wikipedia, traditional notions about academic and educational integrity and appropriate acknowledgment of sources seem altogether out of synch with everyday, creative or artistic research and writing practices. Rarely do students' everyday experience of the Internet include an awareness or consideration of ownership or authorship, much less of plagiarism; rather, the Internet is a space to be filled with status updates and information exchanges, often without reciprocity. Students have developed and normalised their own internal individualised criteria for selecting, evaluating and using information - what this paper will refer to as an everyday or 'home-based' literacy. These home-based literacy practices will vary among students with Internet experience. In addition, some students may have no previous experience with these practices, instead developing home-based literacy

The International Journal for Educational Integrity is available online at:

http://www.ojs.unisa.edu.au/journals/index.php/lJEl/

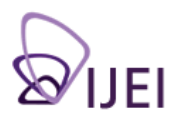


skills in association with other writing and information-gathering practices they engage in every day through exposure to digital technology. Depending on factors such as age, geography, social class and economic resources, students will have various experiences with digital technologies: primary students may have played the videogame Animal Crossing and developed home-based literacy practices by socializing with their family and friends, while secondary and tertiary/college students will probably have more varied exposure to both videogame and Internet practices that will have impacted on their home-based literacy. It is this latter group - the secondary and tertiary/college students with access to varied forms of digital technology - who will be the primary focus of the literacy discussion in this paper.

Many of these contemporary digital skills are acquired incrementally and experientially, rather than being overtly taught in educational settings, or noneducation settings for that matter. So, why talk about them as a form of literacy? At a very basic level, literacy is understood as referring to reading and writing in culturally acceptable ways (Gee, 2008, p. 5). As there is no one 'correct' way of reading or writing, there are many literacies that include many different ways of reading a given text in a given way with the appropriate understanding for a given community. The New London Group (New London Group, 1996) put forward the idea of "multiliteracies" as an approach to literacy pedagogy at a time when digital literacy was not a common phrase (p. 60). Their argument was that literacy goes far beyond reading and writing and is being heavily influenced by new technology (p. 61). The role and influence of technology on communications and pedagogy is an argument which still holds strong today, especially given the rapid uptake of new media technology, which is increasingly available in and out of classrooms.

The difficulty with the term "multiliteracies" is that it is fundamentally contextual and cultural. Literacy is always situated in society, with a variety of reading and writing practices dependent on their context. Part of literacy development is the concomitant acquisition of the discourse that accompanies that literacy, which might include appropriate ways "of behaving, interacting, valuing, thinking, believing, speaking, and often reading and writing, that are accepted as instantiations of particular identities (or 'types of people') by specific groups" (Gee, 2008, p. 3). In this way, literacy is never simply reading and writing, but also includes language, the correct use of that language, and an associated sense and communication of identity. Literacy therefore goes beyond the simple and literal acts of reading and writing, since "the practices of social groups are never just literacy practices, [t]hey also involve ways of talking, interacting, thinking, valuing, and believing" (Gee, 2008, p. 45). Social practices are always an important part of literacy, and displaying a proficiency in these indicates an individual's acquisition of appropriate literacies and a grasp of context-specific discourses.

This of course means that there are also 'wrong' or illegitimate and unauthorised ways of portraying an identity when engaged in a discourse, or with a social group. Correct literacy practices in social situations often go unnoticed simply because they are correct, as their ease of use normalises them in particular contexts and group activities. However, incorrectly demonstrating a particular literacy in a social situation can lead to awkward conversation and odd glances. In virtual environments, incorrectly worded phrases or misused words may lead to a user being ignored, or made fun of. By thinking about academic literacy as a set of particular practices suitable for academic discourse communities, breaches of academic integrity become more clearly understood as a misuse of socially acceptable practices, or as a lack of understanding by the student in how to correctly portray their 'academic', rather than social or online identity. In an educational setting, interpretations of what academic integrity means, and whether research and writing practices are either correct or incorrect is part of the literacy practices of the discourse community. To learn a literacy, "one is socialised or enculturated into a certain social practice" (Gee, 2008 , p. 48). Socialisation and enculturation occur as students begin to learn to 
communicate within school settings, and eventually within their discipline of choice at the college or university level.

Extending this understanding of literacy as part of social practice to the domain of new media, digital literacy then becomes "a shorthand for the myriad social practices and conceptions of engaging in meaning making mediated by texts that are produced, received, distributed, exchanged, etc., via digital codification" (Lankshear and Knobel, 2008 , p. 5). In defining digital literacy, Bawden (2008, p. 18-19) describes the various practices for finding information and using it in everyday life as an important conceptualisation that educators must be explicit about 'unpacking' so that students can start to identify the range of ways in which information may be authored, curated, interpreted and used. This means also emphasising the different skills students might use in accessing different aspects of the Internet. For instance, the use of email or social networking sites are perhaps not as important to the building of academic literacies and ethical research and writing practices as the more interpretative Internet searching skills where finding, understanding, evaluating and then using information is prioritised.

A focus on everyday online practices allows for an understanding of digital literacy as reading and writing in digital spaces - to become meaningful to the consideration of the use of digital space in academia, as well as of academic literacies. Focusing on identifying appropriate practices to find and decipher information for different contexts or purposes means that digital literacy can be interpreted as having correct and incorrect practices. When applied within academia, it is the inappropriate research and writing practices and the resulting misappropriation or misuse of information that leads students to breach academic integrity expectations. With so much information available so easily on the Internet, students enter the classroom with considerable but untutored experience locating evidence, decoding language and discourses, and joining communities. They are encouraged to build on these 'amateur' methodologies through their educational institutions' increasing emphasis on and use of online information and resources, including journal databases. Problems arise when students use their habitual or everyday online research and writing strategies to manage information in academic contexts.

However, this paper suggests that students' everyday Internet usage has led to the development of home-based literacy practices that can be harnessed to encourage them to evaluate the information they find online. Hunting for research material through an academic search engine like EBSCO is not very different from using Google's search capacities. However, the student must decide to use academic literacy practices to evaluate the information from EBSCO differently from the information found on Google, while also appreciating why they should not rely on Google to find the peer-reviewed sources that are considered appropriate for their academic studies. Digitally literate students already have the foundations for these more academic skills, and when these are compared and tapped into in the classroom setting, they can be bridged to include discourse community specific literacy practices that will help them determine how to use the Internet and digital technology more appropriately and effectively in academic contexts.

The problem is that "literacy in the general sense of literal encoding and decoding is not the literacy that confers access to the learning that counts scholastically for school success" (Lankshear and Knobel, p. 10). Specific school-based practices and social uses influence the literacy used in a particular school setting or cohort of students, and this will have an impact on the academic success of these students. Currently, many school practices and social uses are influenced by the digital world and technologies. For instance, in a survey of 233 college students Messineo and DeOllos (2005) found that students report a lack of comfort and experience when "tasks become more challenging" (p. 53). They go on to suggest that "upper-level students expressed reduced confidence in their skills precisely as they faced the more 
challenging applications in class" (p. 53). When specifically asked, "students identify the academic use of IT as more challenging than personal applications" (p. 53). In home usage, with more familiar (though not necessarily simpler) tasks, students report comfort with their digital skills. Unsurprisingly, with more advanced academic applications of their digital skills, students report less confidence, just as they would in other fields or skill development situations. Far from initially bolstering confidence in research and writing tasks, their quickly realise that their adeptness in accessing online information and their proficiency in online communications in social networking sites can actually be a deficit. So the questions to be asked include: How is it that students can become proficient in applying their digital skills in academic settings; what are the implications for their appropriation of academic literacies; and how will these improve their understanding of academic integrity?

If socialising is an effective way to join discourse communities, then tying social practices to academic literacy development can be an effective way of clarifying understandings about academic integrity. Academic integrity - which includes issues of plagiarism, information evaluation, ethical research and writing, and idea ownership, to mention just a few aspects - is taught as part of a general exposure to academic literacy. The challenge for students is that academic integrity is often taught indirectly, so that it is only directly addressed when there is a problem and when scholarly expectations have been breached. General exhortations not to plagiarise are relatively common, but direct conversation or engagement with the topic of academic integrity and the appropriate use of digital media, that draws on examples from students' existing everyday media use, are rare.

In building on Gilster's (2006) definition of digital literacy, Bawden (2008) points out that an expanded and flexible definition is the most helpful. Gilster, importantly, did not create a list or prioritise the digital skills a person has to acquire and be familiar with to be characterised as digitally literate. Instead, Gilster focused on the useful skills a person acquires to operate technology in their everyday life. In a school and university context, this focus would be on the skills a student needs to be digitally literate in their research and writing, to avoid academic integrity issues that are caused by misuse of digital practices. Since students come to academia with a variety of digital literacy skills, the academic digital literacy skills that must be built differ according to student cohort, educational context and previous access to media. It is therefore advisable to approach each classroom with an open mind, ready to discuss and evaluate a cohort's existing digital media skills. This can then lead to a contextualised discussion of the practices appropriate to maintain academic integrity. Instructors can better approach the classroom prepared to assist students in acquiring academic digital literacy skills that will help them throughout their academic career, and which will help them understand and enter into their discipline specific discourse community. Messineo and DeOllo (2005) and Johnson (2008) recommend surveying students in the class to determine the range of experience and comfort an individual class has with digital literacy practices, especially those specific to academia, as the best approach instructors have to provide information about the digital practices students need help with.

Traditionally, as instructors we often respond to academic integrity issues after the event. In my own experience, I have had students in my college level basic writing course ask me "how-to" questions about citations in PowerPoint presentations after their other professors have threatened them with accusations of plagiarism, failing grades and class dismissal due to breaches of citation practices in their class presentations. I have had other students ask me about a college professor re-using questions from a quiz on a test. In this last situation, students enrolled in an online course simply copied and pasted their answers into a digital quiz, as they had access to their previous answers of the same questions. It was only after students failed that portion of the test that the professor discussed the dangers of self-plagiarism when enrolled in online college courses. However, this discussion was in reaction to an 
isolated incident, and after the event, rather than an early broaching of a shared understanding of the issue based on the traps inherent in the delivery mode of the course itself. At no time during the semester were academic integrity issues discussed, as the professor assumed that students understood the broader concept of plagiarism as well as the more complex nuances of self-plagiarism (ironically, the professor's own self-plagiarism evident in his practice of repeating questions was not at issue in this discussion). Prefacing academic integrity information, especially in college courses delivered online, is especially important since the medium allows students access to so much unsorted written material. Unfortunately, there is no opportunity for students to simply order from a list of available academic skills, as if from a menu of appropriate scholarly attributes. To pass the literacy test in academia they must be given the opportunity to learn it, by either direct discussion or by learning from models of appropriate behaviour. In home-based situations, especially videogames, players and students learn through a process of trial and error. In academia, an error on a final project results in a failed grade, with potential for further academic consequences depending on the integrity transgression. When the consequences students are familiar with in home-based practices do not carry across to academic settings; the consequences of academia can seem even more extreme since they are so unfamiliar to the average student. By critically reflecting on the ways that their own literacy of academic integrity is demonstrated, teachers can both model and provide direct instruction on how academic integrity issues should be understood and addressed in academia.

Understanding what practices students come to the classroom equipped with, and understanding the practices necessary to maintain academic integrity, occupies most of the struggle in teaching digital practices in academia. Instructors require the understanding and means to present these practices in the classroom in a way that makes them accessible to the students. The following are some examples of methods to introduce digital literacy practices into the classroom, drawn from the author's experience teaching college-level classes at an American higher education institution. This list is by no means exhaustive, and depending on the experience and access to media technologies of a particular student cohort, they may not be applicable. However, they do provide an illustration of how quite simple discussions of everyday or home media usage can illuminate expectations for both academic literacy skill development and an understanding of issues relating to academic integrity.

One important aspect of academic digital literacy is the ability to find useful information, and use it correctly in assignments. A way of broaching this subject is to start with a consideration of one of the most frightening concerns in the online community: the threat of identity theft. Because of this concern, many Internet users have found ways to spot real URLs and phony URLs, and other online traps, especially when using credit card information. Looking for web addresses that start with https is one of the easiest ways to tell the site being used is a protected site. Looking at the URL redirects for odd messaging is another.

In everyday Internet usage, students develop ways of legitimating the site they are using. Using this process of familiarity and legitimating as a tool to discuss the veracity of online sources, and what counts as a 'good' or reliable source is a useful means of bridging home-based literacy practices within academic settings. Bringing examples of similar information from legitimate and non-legitimate web pages to the students' attention is a good way to begin the discussion. Looking at Wikipedia first, and then validating the information on a government website or other more 'official' and credible sites, is a good way to start the discussion. This then brings attention to an understanding of what makes good primary research information, as well as how the search is conducted and the importance of that search to the research project. 
Statistics have become a reliable index for today's students of the legitimacy of a product or information: when "four out of five dentists recommend a specific

toothpaste", the toothpaste brand begins to carry weight in the mind of the consumer, even without justification or verification of the statistical analysis. Students often apply this model to their own research, looking for statistics to corroborate their point-ofview, and to assist them in making valid arguments. The procedure is often a basic Internet search, and use of the first statistics returned in the results. To counter this practice, first talk about the need to examine the source of the report and ask critical questions, for example: Who funded the survey? Then discuss how valuable random statistics actually are (or are not) in academic research. Directly discussing such practices will help students to be more overtly aware of the more rigorous academic practices they are being exposed to, instead of simply being warned off bad practices.

In addition to accessing information, and using information, students are commonly exposed to various group activities. In many digital practices, online collaboration is common, with citation, equal work distribution, and academic format being activities that do not necessarily involve fun or playful practices. Take examples from video and online games played today, that can increase collaborative in classroom settings. Jane McGonigal (2008) wrote about the fan community that amassed clues and information about an online game called I Love Bees, a sneak preview of the game Halo 2. McGonigal calls the work submitted by the fans an example of "collective intelligence", considering their work to be "the cultural production and consumption of knowledge" (p. 199). In her videogame example, players created blogs, wikis, email and phone-based networks to collect information and produce knowledge in order to dissect clues and gather relevant insight to complete puzzles. The players were able to gather, sort and organise information in sophisticated ways, but were never required to cite the materials they collected. Similarly, within the classroom setting, some students are very good at amassing and locating information, but their homebased literacy practices have never required that they cite their sources. Working creatively with ideas of collective intelligence, academic literacy practices of citations and peer-reviewed sources will help students understand how to turn their information hunting skills into research, collaboration, and citation skills appropriate to the academic setting. Such direct instruction on what is valued in academia, and how it is both similar and dissimilar to the home-based practices students may already be familiar with (or recognise) ensures students are exposed to the practices as readers and writers of academic papers. Specific instruction about the different value systems is a direct method to help bridge the understanding of home-based skills and academic skills.

Collaboration in the classroom is an entirely different interaction, one that can very easily lead to cheating and copying to complete the assignment faster. Quick approaches to completing assignments that do not take academic integrity into account, but model group work, are often experienced when participating in everyday online activities. Clay Shirky (2008) describes a different type of orientation towards digital collaboration, with a more appropriate model for academic integrity concerns. Shirky tells the story of a woman who lost her cell phone in a New York taxi cab and the collaborative effort by her digital friends to recover that phone. Different friends used their available digital networks to reach out to other friends, spreading the information, location, descriptions, and any information that was available and relevant so that their line of communication was spread through the appropriate channel. In outlining group work in this way, Shirky illustrates a collaboration of people who engaged in group work that exemplifies academic integrity. Allowing the homebased literacy practices available to each group member to inform the decision on how a given message should be disseminated encourages the individual to determine what they understand about the message, and critically evaluate their available methods of dissemination. Some people could text, others Tweet, still others update their FaceBook status. In this way, the model for group work is both successful in digital cyberspace, and can allow for bridging of academic integrity issues, as it relies on the individual to make decisions about the information they have available and the 
channels they have access to, in order to play their part in a team effort. Cheating and copying become less relevant, as the student is accessing their own networks of information in order to bring them to the groups' attention. Designing a group assignment that allows for this freedom of interaction is more difficult. It might be more appropriate to assign a broad research topic or question that could allow a group the freedom to determine not only what roles are needed to successfully complete the assignment, but the freedom to also choose who could best serve those roles. Pushing the boundaries of common group work activities in the classroom is a necessity, one that is based on the group work practice students are experiencing in everyday life. Attempting to force students to leave their collaborative skills at the door when they enter the classroom will simply encourage academic integrity issues of copying, cheating, and non-participation because their familiar role as a collaborator is being questioned within academia.

Working with the changing nature of literacy in the digital environment, and the practices associated with it, is complicated. This work also includes understanding how language usage has an impact on literacy skills, because using the correct language can make someone a recognised member of a group, or signal their status as an outsider. Understanding the natural shifts that already occur with language usage as we move between groups helps students understand how to acquire language appropriate to the academic setting. One of the easiest ways to introduce students to ideas about academic integrity is by demystifying academic discourse. Many students will own up to speaking 'bad' English at home, a discussion that can segue into ideas about academic integrity. When discussing English language usage at home, in my classrooms I often move immediately to talking about text messaging on mobile phones. Many, if not most tertiary/college students have a cell phone. Many of their parents also have cell phones. Informal class surveys can tell a teacher how effective cell phone discussions will be based on phone usage amongst students in a given class. Talking about text messaging is also a helpful way to gauge the experience of a given class with this particular technology. When conversing about 'bad' English at home, I ask the class how many of them text their friends. This is often very popular. I then ask them how many text their parents. Again, this practice is becoming more popular. In the classroom, this offers an opportunity to introduce tone, language use and audience reception in academia, the language students often think of as 'good' English and how it functions in academia. By starting a discussion with students about text message language and etiquette they use with their friends and the language they use with their parents, ideas about academic discourse can naturally be introduced to the conversation: including ideas about the purpose of academic discourse and how to figure out how and when to use it. It is also helpful to discuss moments when friends and parents fail to communicate through text message, using incorrect or unfamiliar 'lingo'. In this way, the literacy practices that surround the uses of modern technology can be used to bridge the understanding of the language of academia and the subject it conveys. Helping to demystify academic discourse can be as easy as reminding students how they first learned what emoticons and text-based abbreviations meant and when to use them. A phrase most secondary and tertiary/college students are familiar with is LOL, "laughing out loud'. Having students describe appropriate moments to use LOL, and what it communicates, allows them the space to feel knowledgeable about a specific discourse. Explaining how odd and awkward it is to try to explain that usage to parents can also lead to a discussion of how students learn academic discourse, and the discomfort they may feel while encountering this genre of language for the first time.

There are many good ways to discuss insider and outsider status based on language usage. One example is to discuss the proper usage of "pwnd" (there are several other spellings) in videogames cultures. When a player obliterates or decimates their opponent, quickly defeats, or in many various ways beats their opponents (the actual activity really depends on the game), the winner will then taunt the loser by saying "you got pwnd," or simply "pwnage." In many uses "pwnd" is deliberately misspelled, 
and to misuse the term signals your status as a new player (or 'noob' status) to that game. Correctly using the term after defeating an opponent demonstrates the player's advanced or 'insider' status. Correctly using terms in academia signal membership in similar ways. As instructors, we have all encountered tactics in student's papers where a student used a thesaurus to increase the syllables of every other word in their paper, without increasing the sophistication of their argument or analysis. Having a thesaurus tool available through word processing programs can be detrimental to the writing of some students, especially when they believe increasing the syllables is all that is necessary to advance the level of argument in their paper. Instead, as instructors, we see their usage of terms as demonstrating their novice status within the community, just as gamers identify the misuse of "pwnd." Discussing the proper usage of terminology, the proper use of applications within word processing programs, and the proper layout for papers and how these skills make up practices within academic digital literacy can all be bridged from discussions about terms such as "pwnage".

Understanding academic discourse seems only tangentially related to issues about academic integrity, however, when language is considered as part of the tool kit that allows humans to interact and communicate it is obvious that language does more than just communicate meaning; it both communicates meaning and confers identity. Taking on the role of belonging to a particular academic discourse is an important way to internalise accepted literacy practices in academia, and to internalise ideas of academic integrity that accompany that identity. Contemporary educators need to recognise that our students have varied backgrounds and opportunities to accumulate a range of experience using digital technologies, and that these have led to the development of home-based literacy practices used to navigate a burgeoning digital environment and culture. When teaching academic integrity in the classroom, the literacy practices students already have need to be taken into account to ensure that students more effectively internalise ideas about appropriate discourse, plagiarism, citation, and fair use of information and ideas. If home-based literacy practices are ignored, and students are simply required to adopt the foreign and exceedingly formalised scholarly literacy practices, there will be resistance and misunderstandings. These misunderstandings can easily lead to violations of academic integrity simply because the practices do not coincide with the practices that the students are already familiar with. Maintaining a shifting definition and idea of literacy allows the educator to gauge the existing practices of the individual class or a particular cohort of students, and they can then bridge the gaps in understandings or differences in approach to incorporate discussions about academic integrity and academic discourse in the digital literacy practices already in use by students.

\section{About the author}

Nicole Pfannenstiel is a doctoral student at Arizona State University in Rhetoric and Composition. She earned her MA degree in English from ASU in 2008. Nicole's research addresses topics surrounding new media, the use of new media, discourse in online environments, identity in online environments, and literacy. The idea that ties her work together is the way identity develops through literacy in environments, and the ability to shift discourses with contexts.

\section{References}

Aronowitz, S. \& Giroux, H.A. (1991). Postmodern Education. Minneapolis, MN: University of Minnesota Press.

Bawden, D. (2008). Origin and concepts of digital literacy. In C. Lankshear and M. Knobel (Eds.) Digital Literacies: Concepts, Policies and Practices. New York, NY: Peter Lang Publishing, 17-32. 
Gee, J.P. (2007). What Video Games Have to Teach us About Learning and Literacy. New York, NY: Palgrave-Macmillan.

Gilster, P. (Ed.). (2006). Digital fusion: Defining the intersection of content and communications. In A. Martin \& D. Madigan (Eds.). Digital Literacies for Learning. London: Facet Publishing, 42-50.

Johnson, G.M. (2008). Functional Internet literacy: Required cognitive skills with implications for instruction. In C. Lankshear and M. Knobel (Eds.) Digital Literacies: Concepts, Policies and Practices. New York, NY: Peter Lang Publishing, 33-45.

Lankshear, C. and M. Knobel (2008). Introduction. In C. Lankshear and M. Knobel (Eds.) Digital Literacies: Concepts, Policies and Practices . New York, NY: Peter Lang Publishing, 1-16.

McGonigal, J. (2008). Why I Love Bees: A case study in collective intelligence gaming. In K. Salen (Ed.) The Ecology of Games: Connecting Youth, Games and Learning. Cambridge, MA: The MIT Press, 199-227.

Messineo, M. and DeOllos, I.Y. (2005). Are we assuming too much? Exploring students' perceptions of their computer competence. College teaching, 53, 5055.

New London Group (1996). A pedagogy of multiliteracies: Designing social futures. Harvard Educational Review, 66, 60-92.

Tapscott, D. and A.D. Williams (2006). Wikinomics: How Mass Collaboration Changes Everything. New York, NY: Penguin Group.

Shirky, C. (2008). Here comes everybody: The power of organizing without organizations. London, England: Penguin Group.

Werde, B. (2004). Arts briefing: Highlights, grey album downloads. New York Times, 2 March, p. 2. 